by increases of grant sufficient for their gradual reduction. Considerable items of capital expenditure still call for the Ministry's contribution on a pound for pound basis; but if possible, smaller items should be met out of a margin provided by an adequate annual grant.

As a measure of security for the proper use of the suggested increased grants, the report proposes that annual visits should be paid to colleges and farms by responsible officials and technical officers of the
Ministry. It also recommends that members of the county committees should periodically visit any college to which a grant is made, with the view of increasing the co-operation between colleges and counties.

If the suggestions outlined above are put into force, the position of the agricultural colleges of Great Britain will be greatly strengthened, and they will be enabled to make a much greater contribution towards improving agricultural practice throughout the country.

\title{
International Longitude Operations
}

$\mathrm{T}$ HE Observatory of Zi-Ka-Wei, which took part in the International Programme of Longitude Operations in October and November 1933, in addition to transmitting its results to the Commission of the International Astronomical Union responsible for the general reduction of the whole work, has published its own observations in its Annales (t. 20).

The Observatory kept its own time with two pendulums, Leroy 1227 and 1338, working at constant pressure and a temperature controlled by a thermostat. Meridian observations were made with two transit instruments, the $\mathrm{Zi}-\mathrm{Ka}$.Wei instrument used in 1926 and a similar instrument which was brought from Nice by M. Fayet. Observations with both instruments were secured on twenty-eight nights by four observers, each of whom used both instruments. The maximum difference between the clock errors deduced from the two instruments on the same night was $0 \cdot 04^{\mathrm{s}}$, and the difference was generally less than $0.02 \mathrm{~s}$. Wireless time signals were received from a number of stations, including DFY (Nauen) and FYL (Bordeaux). Time lags in the reception of the wireless signals were determined by a method due to M. Jouast, and it is hoped that their effect has been eliminated. The longitude of $\mathrm{Zi}-\mathrm{Ka}$-Wei minus Paris is found to be $7^{\mathrm{h}} 56^{\mathrm{m}} 21.962^{\mathrm{s}}$ in 1933 , as compared with $21.975^{\mathrm{s}}$ in 1926. The difference between the two determinations is thus $0.015^{\mathrm{s}}$ (the equivalent of $17 \mathrm{ft}$. on the earth's surface) which is presumably scarcely outside the limit of accidental error ; but it is of interest from the point of view of continental drift to note that observations of this kind would certainly have shown up a drift of seventy feet on the earth's surface during the seven years that elapsed between the two determinations. It is certain that the reality or otherwise of continental drift will be settled by these precise longitude observa. tions, when a long enough time interval has elapsed.

The director of the $\mathrm{Zi}-\mathrm{Ka}$-Wei Observatory directs attention to a puzzling periodic variation from the mean longitude with an amplitude of $0.05^{\mathrm{s}}$ and period of one month. This is shown by the 1933 observations as well as by those made in 1926. $\mathrm{He}$ concludes that it is not possible to incriminate either the meridian observations or the reception of the time signals, and is inclined to attribute these fluctuations to a periodic deformation of the earth's crust. One is reminded of a somewhat similar effect in the longitude difference Washington minus Greenwich, which has been pointed out by Loomis and Stetson. The precise nature of the cause of this variation is obscure.

\section{Biology and Variation of Ceratium}

\begin{abstract}
WHE introductory report* (No. 1) to the Carlsberg Foundation's Oceanographical Expedition contains an article in memory of its late leader, Prof. Johannes Schmidt, by Martin Knudsen, with portrait, a foreword by P. Jespersen and $\AA$. Vedel Tåning, a list of stations and, finally, the results with detailed tables of the echo-soundings, with introductory remarks by Sv. Greve. There are also seven maps showing the stations.

This was the last and the greatest of the many expeditions in which Schmidt personally took part, from June 14, 1928, until June 30, 1930. Like all those which he conducted, it was planned and con-

* The Carlsberg Foundation's Oceanographical Expedition round the World 1928-30 and Previous Dana Expeditions under the Leadership of the late Prof. Johannes Schmidt. Dana-Report No. 1. Introduction to the Reports from the Carlsberg Foundation's Oceanographical Expedition round the World 1928-30. Pp. $130+7$ plates. 168. net. No. 4. Untersuchungen über die Verbreitung, Biologie und Variation der Ceratien im sidiliches stillen Ocean, von E. Steemann Nielsen Oxford University Press, 1934.)
\end{abstract}

ceived in every detail by himself. He took care that the investigations were as many-sided as possible, and maintained his interest in discovering connexions between the biological and physico-oceanographical conditions. The principal features in the biologicalzoogeographical methods of work and the plans for the Expedition were drawn up by him in the following summary :-

(1) With the aid of the most efficient apparatus to obtain a very large material, rich in individuals, of the pelagic life in the different depths and the various oceans.

(2) With the aid of simultaneous, methodical investigations on the physical and chemical com. position of the different water layers, to obtain data which would permit us to conclude under what environmental conditions each single one of the millions of pelagie organisms, taken in the nets, may live. 